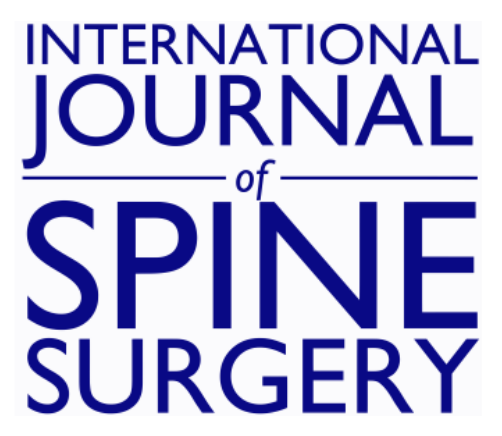

\title{
Lumbar Pedicle Morphology and Vertebral Dimensions in Isthmic and Degenerative Spondylolisthesis--A Comparative Study
}

Dhruv K.C. Goyal, Daniel A. Tarazona, Anand Segar, Ryan Sutton, Michael A. Motto, Srikanth N. Divi, Matthew S. Galetta, Alan S. Hilibrand, Ian D. Kaye, Mark F. Kurd, Kris E. Radcliff, Jeffrey A. Rihn, D. Greg Anderson, Christopher K. Kepler, Victor Hsu, Barrett Woods, Alexander R. Vaccaro and Gregory D. Schroeder

Int J Spine Surg 2021, 15 (2) 243-250

doi: https://doi.org/10.14444/8009

http://ijssurgery.com/content/15/2/243

This information is current as of April 25, 2023.

Email Alerts Receive free email-alerts when new articles cite this article. Sign up at: http://ijssurgery.com/alerts 


\title{
Lumbar Pedicle Morphology and Vertebral Dimensions in Isthmic and Degenerative Spondylolisthesis-A Comparative Study
}

DHRUV K.C. GOYAL, MD, DANIEL A. TARAZONA, MD, ANAND SEGAR, MD, RYAN SUTTON, BS, MICHAEL A. MOTTO, MD, SRIKANTH N. DIVI, MD, MATTHEW S. GALETTA, BA, ALAN S. HILIBRAND, MD, IAN D. KAYE, MD, MARK F. KURD, MD, KRIS E. RADCLIFF, MD, JEFFREY A. RIHN, MD, D. GREG ANDERSON, MD, CHRISTOPHER K. KEPLER, MD, MBA, VICTOR HSU, MD, BARRETT WOODS, MD, ALEXANDER R. VACCARO, MD, PHD, MBA, GREGORY D. SCHROEDER, MD

Department of Orthopaedic Surgery, Rothman Orthopaedic Institute, Thomas Jefferson University, Philadelphia, Pennsylvania

\begin{abstract}
Background: The pedicle screw is the most common device used to achieve fixation in fusion of spondylolistheses. Safe and accurate placement with this technique relies on a thorough understanding of the bony anatomy. There is a paucity of literature comparing the surgically relevant osseous anatomy in patients with a degenerative spondylolisthesis (DS) and an isthmic spondylolisthesis (IS). The goal of this study was to determine the differences in the osseous anatomy in patients with a DS and those with an IS.

Methods: A retrospective comparative cohort study was conducted on patients with a single-level, symptomatic L4-L5 DS or a single-level, symptomatic L5-S1 IS. Magnetic resonance imaging for these patients was reviewed. Morphometries of the pedicle and vertebral body were analyzed by 2 independent observers for the levels from L3 to S1, and radiographic parameters were compared between groups.

Results: A total of 572 levels in 143 patients were studied, including 103 patients with a DS and 40 with an IS. After accounting for confounders, IS and DS had an independent effect on transverse vertebral body width, pedicle height and width, and sagittal pedicle angle. Patients with an IS had a smaller pedicle height $(P<.001)$ and pedicle width $(P=.001)$ than patients with DS. In addition, the angulation of the pedicles varied on the basis of the diagnosis.

Conclusions: The osseous anatomy is significantly different in patients with a DS than with an IS. Patients with an IS have smaller pedicles in the lumbar spine. Also, the L4 and L5 pedicles are more caudally angulated and the S1 pedicle is less medialized.

Level of Evidence: 3.

Clinical Relevance: Understanding the differences in pedicle anatomy is important for the safe placement of pedicle screws.

Lumbar Spine

Keywords: pedicle, anatomy, morphology, isthmic spondylolisthesis, degenerative spondylolisthesis, vertebral body
\end{abstract}

\section{INTRODUCTION}

Spondylolisthesis refers to the anterior slippage of a cranial vertebral body in relation to the adjacent caudal vertebral. Degenerative spondylolisthesis (DS) most commonly occurs at L4-L5 and is caused by degeneration of the facet joints and intervertebral discs. Isthmic spondylolisthesis (IS) most commonly occurs at L5-S1 and corresponds to a lytic defect in the pars interarticularis. ${ }^{1}$

A large portion of symptomatic spondylolistheses are successfully treated nonoperatively; however, patients with persistent pain or neurologic symptoms despite conservative treatment may benefit from surgical management. Lumbar pedicle screw placement is often performed using a "freehand" technique that uses anatomic landmarks to guide the placement of these screws. ${ }^{2,3}$ The safe and accurate placement of pedicle screws with this technique relies on a thorough understanding of the bony anatomy.

To date, there have been multiple studies evaluating the anatomical features of the lumbar spine in an unaffected population. ${ }^{3-6}$ However, there is a paucity of literature comparing the surgically relevant osseous anatomy in patients with a DS and those with an IS. Anatomical differences 
could have implications for surgeons when instrumenting pedicles, especially in terms of pedicle screw size, approach, and angulation. The purpose of this study was to compare the bony morphology in the lumbar spine of patients with a DS and of those with an IS.

\section{METHODS}

After the appropriate institutional board review approval was obtained, a retrospective comparative study of the vertebral bodies L3 through S1 of patients with a single-level, symptomatic L4-L5 degenerative spondylolisthesis or a single-level, symptomatic L5-S1 isthmic spondylolisthesis was performed. The study was conducted at a single, large orthopedic practice with fellowship-trained spine surgeons. Patients with preoperative T1weighted magnetic resonance imaging (MRI) of the lumbar spine (sagittal, transverse, and coronal planes) and symptomatic L4-5 DS or L5-S1 IS documented by the attending spine surgeon were included. Patients with a prior history of lumbar surgery, scoliosis, spondylolisthesis at multiple levels, spinal trauma, an active spine infection, or spinal metastasis were excluded.

All radiographic measurements were performed using Sectra Workstation IDS7 18.2 (Sectra AB; Linkoping, Sweden) by 2 investigators working independently. Radiographic measurements obtained were pedicle height, pedicle width, transverse vertebral body width, coronal vertebral body width, transverse pedicle angle (ie, the medialization of the pedicle), sagittal pedicle angle (ie, the caudal angulation of the pedicle), and lamina-pedicle angle for spinal segments L3-S1 for each patient. ${ }^{3,7}$ These measurements and their definitions are summarized in Table 1.

\section{STATISTICAL METHODS}

Interobserver reliability (IOR) for each radiographic measurement was calculated using the Cohen $\kappa$ coefficient. Similar to a correlation coefficient, the $\kappa$ coefficient can range from -1 to +1 . A value of 0 indicates the amount of agreement due to chance, and 1 indicates perfect agreement. A $\kappa$ value less than $.40, .41-.60, .61-.75$, or .75-1.00 indicates poor, fair, good, or excellent IOR, respectively. Radiographic parameters were first compared between groups using an independent samples $t$ test. Multivariate analyses were then used to account for confounding variables including, age, gender, body mass index (BMI), ethnicity, and spinal level and to measure the independent effects of DS and IS on each radiographic parameter. Statistical significance was defined as a $P$ value of .05 or less. All analyses were performed using SPSS, version 24 (IBM Corporation, Armonk, NY).

\section{RESULTS}

A total of 143 patients were included; 103 had a grade 1 L4-5 DS and 40 had a grade 1 L5-S1 IS. Patient demographics are presented in Table 2. The average age and BMI were 58.6 years and $31.2 \mathrm{~kg} /$ $\mathrm{m}^{2}$, respectively. Patients with IS were on average younger (48.8 vs 62.5 years; $P<.001$ ) than patients with DS, and there were more female patients with IS $(66.0 \%$ vs $45.0 \% ; P=.021)$. There were no differences in terms of BMI $(P=.769)$ or ethnicity $(P=.362)$.

The $\kappa$ coefficients measuring the IOR for pedicle height, pedicle width, transverse vertebral body width, coronal vertebral body width, transverse pedicle angle, sagittal pedicle angle, and laminapedicle angle were $.95, .97, .99, .99, .98, .95$, and .96 , respectively, indicating that the IOR was excellent for all measurements. All measurements are presented in Table 3. Patients with IS had a smaller pedicle height at all levels $(P<.05)$ compared with those with DS (Figure 1A). The pedicle width was similar in both groups, with the exception that the IS group was narrower at L4 (10.6 vs $12.2 \mathrm{~mm}, P<$ .001 ; Figure 1B). The pedicle orientation was also different between the groups. Those with an IS had pedicles with a greater (more caudally angulated) sagittal vertical angle at $\mathrm{L} 4\left(9.1^{\circ}\right.$ vs $\left.5.7^{\circ} ; P<.001\right)$ and L5 $\left(11.8^{\circ}\right.$ vs $7.0^{\circ} ; P<.001$; Figure 1D). Similarly, at S1, patients with an IS had a smaller (less medialized) transverse pedicle angle $\left(29.9^{\circ}\right.$ vs $39.5^{\circ} ; P<.001$; Figure $1 \mathrm{C}$ ).

After accounting for the aforementioned confounding variables, IS and DS had an independent effect on several of the radiographic measurements (Table 2). Patients with an IS had a smaller pedicle height $(P<.001)$ and pedicle width $(P=.001)$ than patients with DS. The IS patients also had a greater sagittal pedicle angle $(P=.001)$ and transverse vertebral body width $(P=.025)$. There was also a trend towards a larger transverse pedicle angle $(P=$ $.074)$ and coronal vertebral body width $(P=.087)$ in those with an IS. There was no independent effect of diagnosis on the lamina pedicle angle $(P=.698)$. 
Table 1. Method of radiographic measurements.

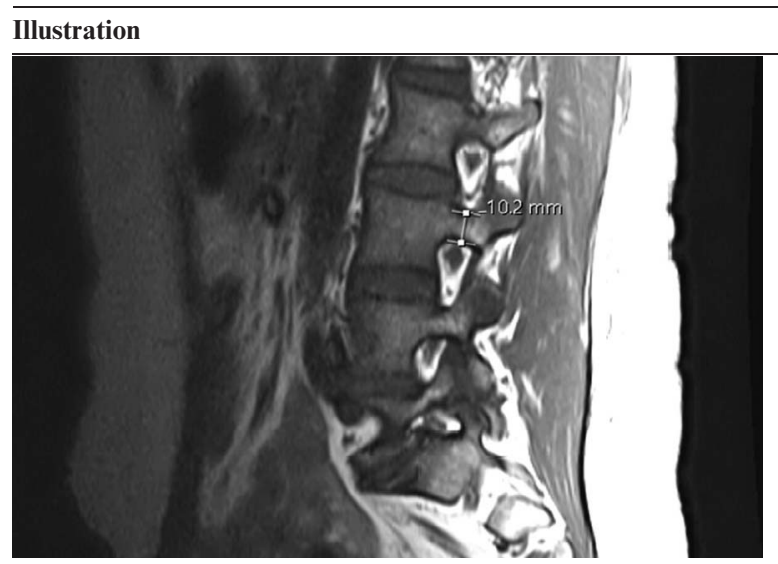

Definition

Pedicle height: the narrowest distance of the pedicle in sagittal plane. ${ }^{3}$

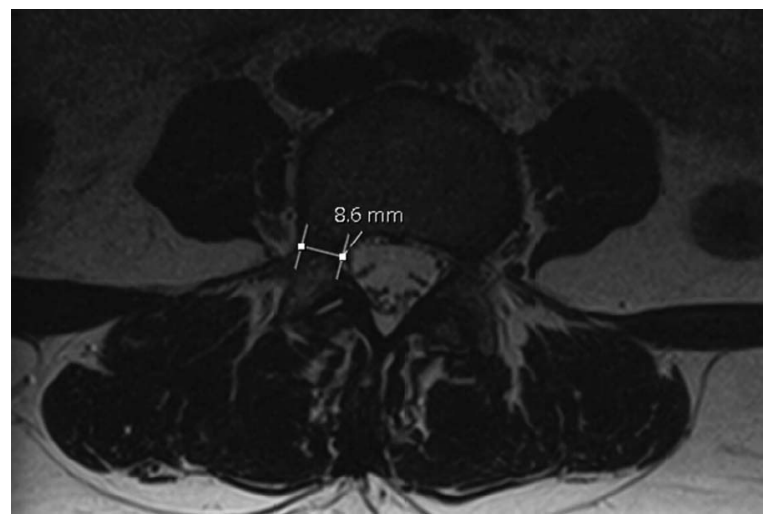

Pedicle width: the narrowest distance of the pedicle in the transverse plane. ${ }^{3}$

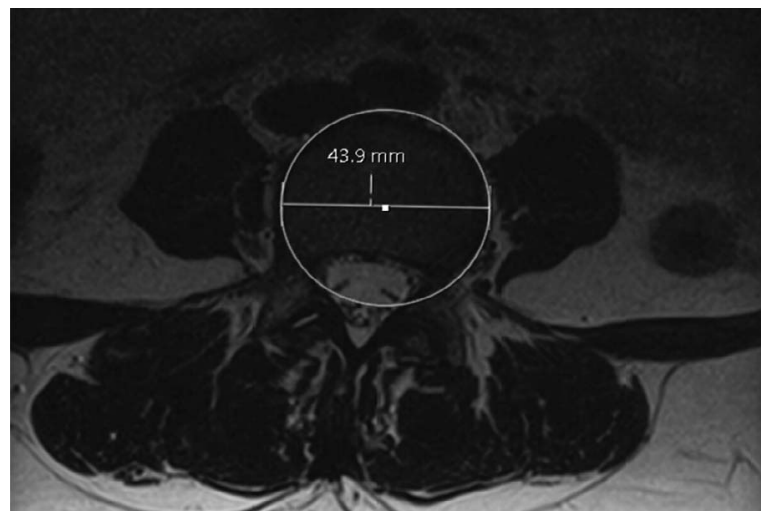

Transverse vertebral body width: the diameter of the best-fit circle of the vertebral body in the transverse plane.?

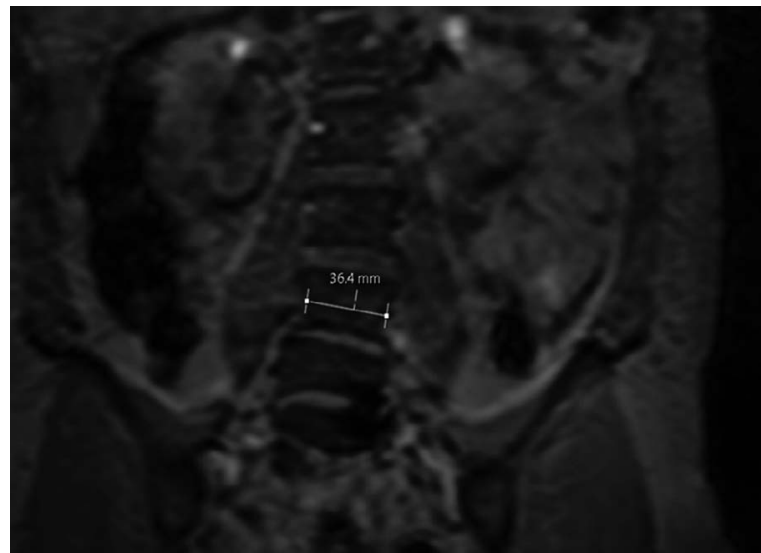

Coronal vertebral body width: the narrowest diameter of the vertebral body in the coronal plane that is parallel to the horizontal. ${ }^{7}$ 
Table 1. Continued.
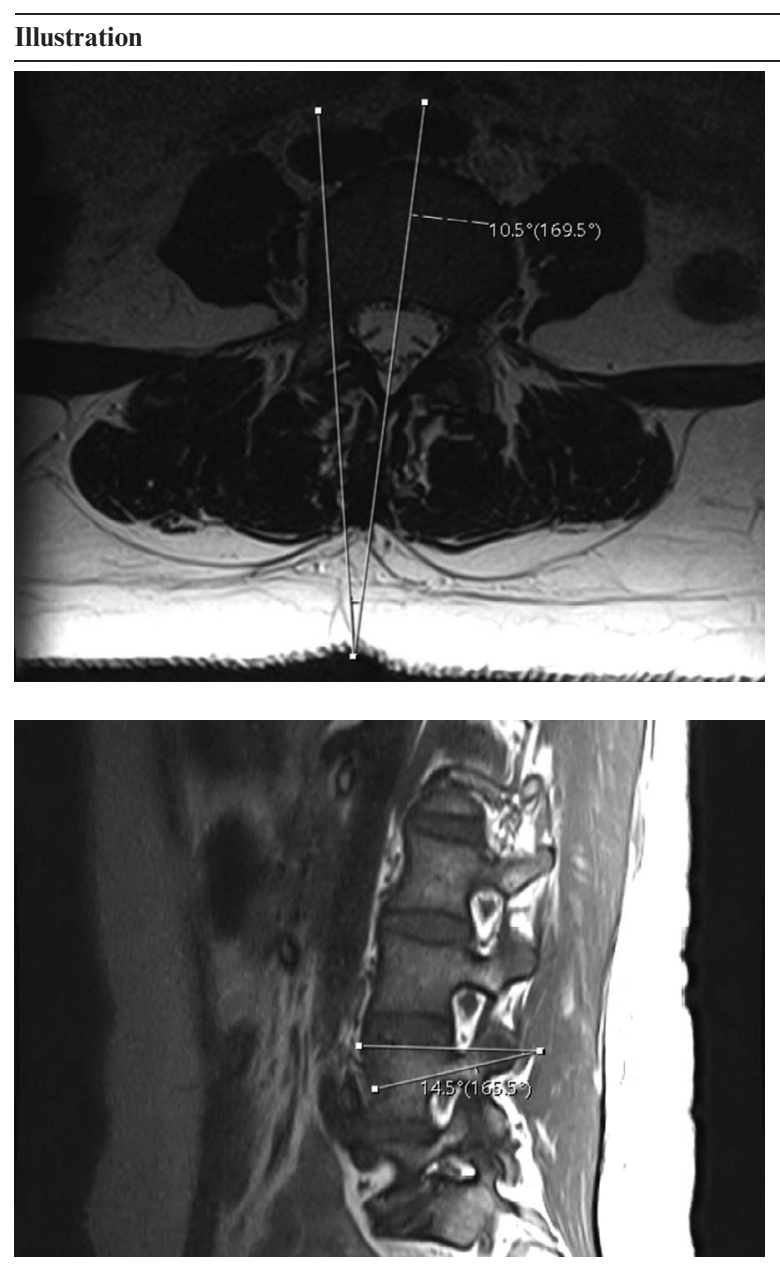

Transverse pedicle angle: the angle between a line perpendicular to the transverse isthmus and a perpendicular bisector of the vertebral body. ${ }^{3}$

Sagittal pedicle angle: the angle between the pedicle axis and the superior border of vertebral body in the sagittal plane. ${ }^{3}$

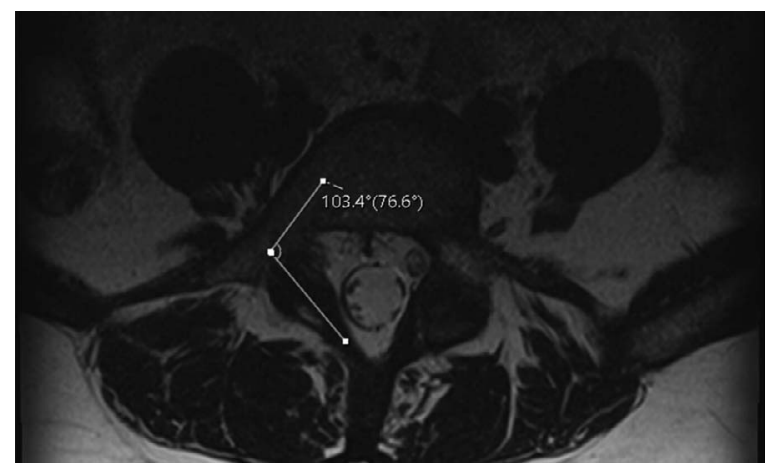

Lamina-pedicle angle: the angle between a line perpendicular to the isthmus of the pedicle and a line perpendicular to the isthmus of the lamina in the transverse plane. ${ }^{7}$

\section{DISCUSSION}

The most commonly performed treatment for a symptomatic spondylolisthesis of the lumbar spine includes an instrumented fusion, often using pedicle screws, with a reported ${ }^{2,8,9}$ implant complication rate between $2 \%$ and $15 \%$. A thorough understanding of pedicle anatomy is critical to safe and successful spine surgery. In addition to avoiding intraoperative complications, understanding the optimal screw placement can also result in improved construct biomechanics and fusion rates.

This study found that the pedicles in IS are uniquely different from those in DS. Once confounding variables were accounted for, the pedicles of patients with an IS had a smaller height and width than the pedicles of patients with a DS. Furthermore, the lower lumbar pedicles were more caudally angled. Notably, the S1 pedicle was less medially angled in patients with an IS. These 
Table 2. Comparison of radiographic parameters between patients with an isthmic spondylolisthesis (IS) and those with a degenerative spondylolisthesis (DS).

\begin{tabular}{|c|c|c|c|c|c|}
\hline & \multicolumn{2}{|c|}{ Degenerative Spondylolisthesis $(\mathrm{n}=103)$} & \multicolumn{2}{|c|}{ Isthmic Spondylolisthesis $(n=40)$} & \multirow[b]{2}{*}{$P$ Value } \\
\hline & Mean \pm SD & $\%$ of DS & Mean \pm SD & $\%$ of IS & \\
\hline Age & $62.5 \pm 11.9$ & & $48.8 \pm 13.9$ & & $<.001^{\mathrm{a}}$ \\
\hline BMI & $31.3 \pm 6.1$ & & $31.0+5.7$ & & .769 \\
\hline Gender, \% & & & & & $.021^{\mathrm{a}}$ \\
\hline Female & 66.0 & & & 45.0 & \\
\hline Male & 34.0 & & & 55.0 & \\
\hline Ethnicity & & & & & .362 \\
\hline Caucasian & & 87.4 & & 92.5 & \\
\hline African American & & 7.8 & & 7.5 & \\
\hline Hispanic & & 4.9 & & 0.0 & \\
\hline
\end{tabular}

Abbreviation: BMI, body mass index.

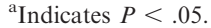

measurements have clinical implications for surgery at the lumbosacral junction.

Roy Camille ${ }^{10}$ was the first to describe the use of pedicle screws with a plating system in 1976. Since then, numerous authors have described normal pedicle anatomy. Panjabi et $\mathrm{al}^{6}$ described lumbar pedicle anatomy on 12 fresh frozen cadavers. Pedicle height, width, transverse angulation, and sagittal declination angulation increased from L1 to L5, ranging from $8.0-19.2 \mathrm{~mm}$ for width, 15.8-19.5 $\mathrm{mm}$ for height, $2.2^{\circ}-5.2^{\circ}$ for transverse angulation, and $12.4^{\circ}-25.9^{\circ}$ for sagittal declination. The authors did not describe S1 anatomy. Zindrick and colleagues ${ }^{4}$ found similar dimensions to Panjabi on computed tomography (CT) scans and roentgenograms of vertebral specimens except for a flatter

Table 3. Comparison of radiographic parameters between patients with an isthmic and a degenerative spondylolisthesis.

\begin{tabular}{|c|c|c|c|c|}
\hline & \multirow[b]{2}{*}{$\begin{array}{l}\text { Degenerative Spondylolisthesis } \\
(\mathrm{n}=\mathbf{1 0 3}), \text { Mean } \pm \mathrm{SD}\end{array}$} & \multirow{2}{*}{$\begin{array}{l}\text { Isthmic Spondylolisthesis } \\
(\mathrm{n}=40), \text { Mean } \pm \text { SD }\end{array}$} & \multicolumn{2}{|c|}{$P$ Value } \\
\hline & & & Bivariate Analysis & Multivariate Analysis \\
\hline \multicolumn{5}{|c|}{ Pedicle height, $\mathrm{mm}$} \\
\hline L3 & $10.33 \pm 1.4$ & $9.42 \pm 1.6$ & $.001^{\mathrm{a}}$ & $<.001^{\mathrm{a}}$ \\
\hline L4 & $10.28 \pm 1.4$ & $9.58 \pm 1.5$ & $.009^{\mathrm{a}}$ & \\
\hline L5 & $10.19 \pm 1.4$ & $9.02 \pm 1.7$ & $<.001^{\mathrm{a}}$ & \\
\hline $\mathrm{S} 1$ & $12.60 \pm 2.5$ & $11.26 \pm 2.2$ & $.004^{\mathrm{a}}$ & \\
\hline \multicolumn{5}{|c|}{ Pedicle width, mm } \\
\hline L3 & $10.00 \pm 2.5$ & $9.11 \pm 3.0$ & .075 & $.001^{\mathrm{a}}$ \\
\hline L4 & $12.10 \pm 2.9$ & $10.63 \pm 2.6$ & $.006^{\mathrm{a}}$ & \\
\hline L5 & $15.51 \pm 3.4$ & $15.02 \pm 3.7$ & .457 & \\
\hline S1 & $19.51 \pm 3.4$ & $19.28 \pm 3.9$ & .730 & \\
\hline \multicolumn{5}{|c|}{ Transverse pedicle angle, ${ }^{\circ}$} \\
\hline L3 & $14.69 \pm 4.5$ & $16.62 \pm 4.4$ & $.023^{\mathrm{a}}$ & .074 \\
\hline L4 & $15.84 \pm 5.3$ & $16.35 \pm 6.2$ & .626 & \\
\hline L5 & $23.36 \pm 8.8$ & $23.17 \pm 7.1$ & .901 & \\
\hline $\mathrm{S} 1$ & $39.47 \pm 10.4$ & $29.94 \pm 15.2$ & $<.001^{\mathrm{a}}$ & \\
\hline \multicolumn{5}{|c|}{ Sagittal pedicle angle, ${ }^{\circ}$} \\
\hline $\mathrm{L} 3$ & $-6.24 \pm-4.9$ & $-9.80 \pm-9.4$ & $.003^{\mathrm{a}}$ & $.001^{\mathrm{a}}$ \\
\hline L4 & $-5.77 \pm-3.5$ & $-9.13 \pm-6.9$ & $<.001^{\mathrm{a}}$ & \\
\hline L5 & $-7.03 \pm-5.9$ & $-11.84 \pm-8.4$ & $<.001^{\mathrm{a}}$ & \\
\hline $\mathrm{S} 1$ & $-21.89 \pm-9.1$ & $-21.15 \pm-10.5$ & .675 & \\
\hline \multicolumn{5}{|c|}{ Coronal vertebral body width, mm } \\
\hline L3 & $51.31 \pm 5.8$ & $49.99 \pm 7.0$ & .284 & .087 \\
\hline L4 & $53.45 \pm 5.5$ & $52.02 \pm 6.5$ & .213 & \\
\hline L5 & $56.38 \pm 6.7$ & $55.56 \pm 6.5$ & .532 & \\
\hline $\mathrm{S} 1$ & $59.35 \pm 6.4$ & $58.88 \pm 6.9$ & .718 & \\
\hline \multicolumn{5}{|c|}{ Transverse vertebral body width, mm } \\
\hline L3 & $44.18 \pm 5.9$ & $45.35 \pm 6.0$ & .295 & $.025^{\mathrm{a}}$ \\
\hline L4 & $47.27 \pm 6.5$ & $47.69 \pm 4.9$ & .713 & \\
\hline L5 & $51.65 \pm 7.7$ & $52.63 \pm 8.2$ & .506 & \\
\hline $\mathrm{S} 1$ & $54.25 \pm 7.4$ & $60.4 \pm 8.0$ & $<.001^{\mathrm{a}}$ & \\
\hline \multicolumn{5}{|c|}{ Lamina pedicle angle, ${ }^{\circ}$} \\
\hline L3 & $112.05 \pm 8.5$ & $109.73 \pm 14.3$ & .236 & .698 \\
\hline L4 & $112.52 \pm 10.8$ & $110.90 \pm 14.9$ & .473 & \\
\hline L5 & $103.62 \pm 10.1$ & $107.71 \pm 10.5$ & $.033^{\mathrm{a}}$ & \\
\hline $\mathrm{S} 1$ & $94.89 \pm 31.1$ & $95.34 \pm 21.1$ & .932 & \\
\hline
\end{tabular}

andicates $P<.05$. 
A

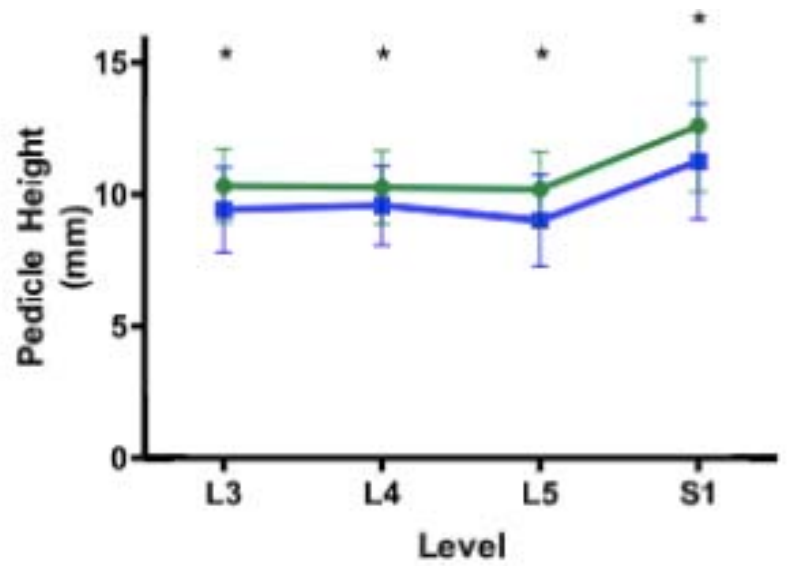

C

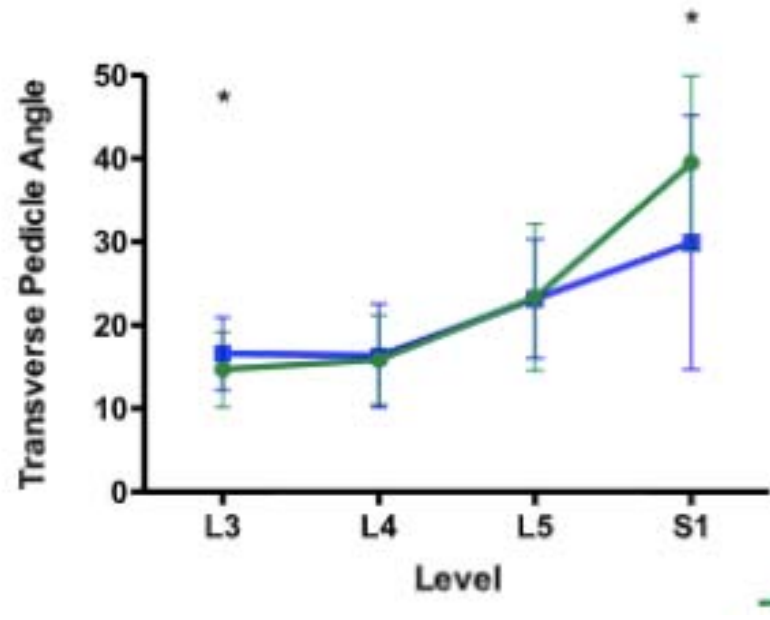

B

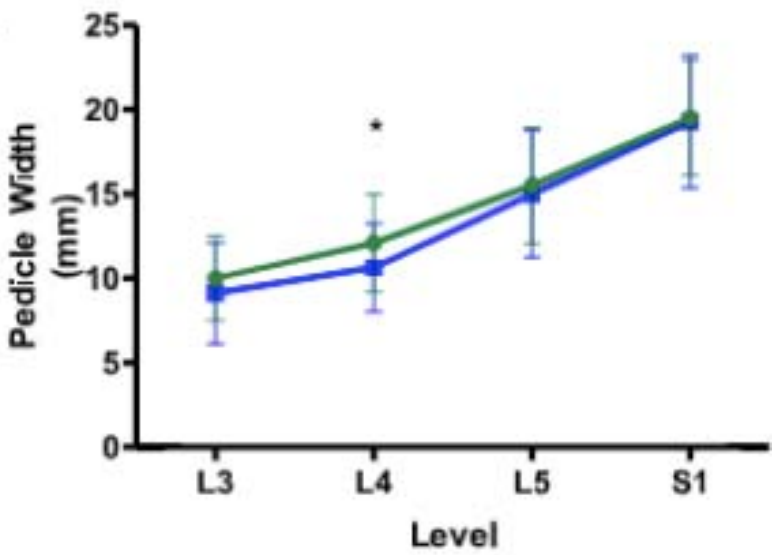

D

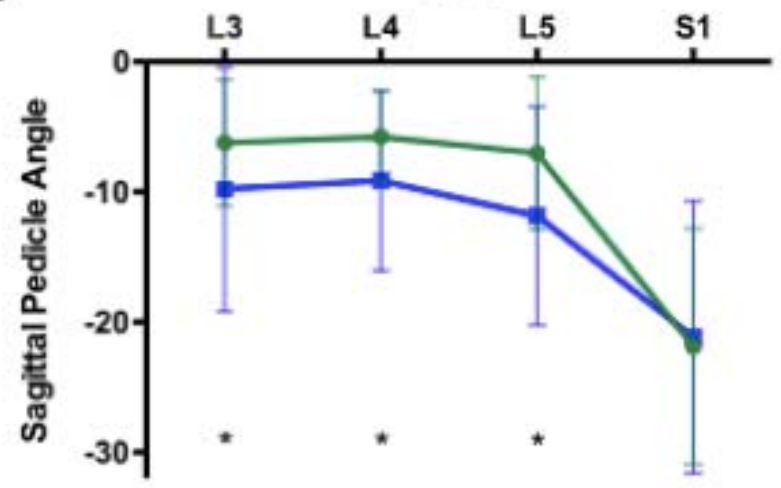

is

Figure 1. Graphical representation of differences in pedicle anatomy in degenerative spondylolisthesis (DS) and isthmic spondylolisthesis (IS). DS represented by green circles and IS represented by blue square. Asterisk indicates $P<.05$.

sagittal pedicle angulation. In comparison with Panjabi et $\mathrm{al}^{6}$ and Zindrick et $\mathrm{al}^{4}{ }^{4}$ Olsewski et $\mathrm{al}^{5}$ found similar pedicle dimensions but less transversely oriented and more caudally oriented pedicles.

Our results demonstrate that the underlying pathology affects the pedicle morphology, and a "one-size-fits-all" approach is not appropriate for spinal instrumentation. However, comparing the actual sizes of the pedicles in the current study with those in previously studies is challenging, because different methodologies have been used in different studies. The current study used MRI because this is the only advanced imaging we routinely obtained. Whereas evaluating the osseous anatomy on CT scans may give a more accurate absolute value for the pedicle size, given the risks associated with radiation, a CT scan is not routinely obtained for all patients at our institution. Furthermore, although the absolute measurements may not be as accurate on MRI as on a CT scan, the comparative morphology should not be affected by the choice of imaging. Moreover, the findings of the current study are similar to those Choi and colleagues ${ }^{11}$ reported when they compared pedicle anatomy in patients with an IS with patients without a spondylolisthesis.

In addition to identifying that the pedicles in a patient with an IS are smaller in height and width, another important finding is that the pedicles are more caudally angulated in IS than in DS. This is independent of the slip angle or lumbar lordosis because the measurement method is normalized to the internal anatomy of each level, and so we postulate that this could be explained by the increased wedging of both the L4 and L5 bodies seen in patients with an isthmic spondylolisthesis. ${ }^{12,13}$ Furthermore, in an operative setting, when a patient is placed prone, this angle may be accentuated, making the pedicle screws even more difficult to place. 
There are only a few studies investigating the morphometric variability of the lumbar spine in IS. Choi et $\mathrm{al}^{11}$ compared CT scans of unaffected participants with those of patients with IS. Similar to our study, the authors found narrower and shorter pedicles in IS, with a higher grade of IS associated with an even smaller pedicle. They also found that both the L4 and L5 pedicles were more transversely oriented in those with IS compared with unaffected individuals $\left(13.7^{\circ}\right.$ vs $9.6^{\circ}$ and $19.2^{\circ}$ vs $12.4^{\circ}$, respectively). Unfortunately, they did not quantify a sagittal pedicle angulation. ${ }^{11}$

Both Choi et $\mathrm{al}^{11}$ and Matthews et $\mathrm{l}^{14}$ found that in the setting of IS the L5, but not the L4, pedicles were up to $4.5 \mathrm{~mm}$ longer and this elongation was unrelated to the extent of slip. Pedicle elongation is further supported by a cadaveric study in which the pedicles were found to be $5.5-6.5 \mathrm{~mm}$ longer than those in a subject without IS or DS. ${ }^{11,14,15}$ It is hypothesized that the elongation occurs as a result of abnormal biomechanical stress, repetitive microfractures, and subsequent healing. ${ }^{14,15}$ Hence, the magnitude of slip is proportional to the length of the pedicle. This is further supported by the fact that in IS, as the pedicle elongates, the vertebral body length does not change. ${ }^{11}$

The current study found that the transverse vertebral body width, measured on axial images, was smaller in IS than DS. This is in keeping with the study by Wren and colleagues, ${ }^{16}$ who found that the vertebral body cross-sectional area was up to $10 \%$ smaller in those with spondylolysis. The biomechanical implications of this are important in the pathophysiology of IS. A smaller vertebral body is associated with increased mechanical stress within the body, earlier fatigue, microfractures, and remodeling, possibly further contributing the morphological abnormalities of IS. ${ }^{17}$

This study has multiple limitations, including all that are inherent in a retrospective radiographic review. The biggest limitation is the fact that MRI scans were used, which have less bony detail than CT scans. However, in clinical practice, it is uncommon to routinely obtain an CT scan, and thus, MRI would be the usual method for preoperative planning. In addition, our studies did not have any patients without instability; however, this study was designed to evaluate patients who may need an instrumented lumbar fusion, and without instability we rarely perform a lumbar fusion. Last, the IS was at L5-S1 and the DS was at L4-L5. We would have liked to compare patients with an IS and DS at the same level; however, given the differences in the most common location of the specific pathology, this was not possible.

\section{CONCLUSION}

The osseous anatomy is significantly different in patients with a DS than in those with an IS. Patients with an IS have smaller pedicles at all levels in the lumbar spine. Also, the L4 and L5 pedicles are more caudally angulated and the $\mathrm{S} 1$ pedicle is less medialized. Understanding the difference in pedicle anatomy in patients with these 2 diagnoses is critical in the safe placement of pedicle screws.

\section{REFERENCES}

1. Hu SS, Tribus CB, Diab M, Ghanayem AJ. Spondylolisthesis and spondylolysis. J Bone Joint Surg Am. 2008;90(3):656-671.

2. Jacobs WCH, Vreeling A, De Kleuver M. Fusion for lowgrade adult isthmic spondylolisthesis: a systematic review of the literature. Eur Spine J. 2006;15(4):391-402. doi:10.1007/s00586005-1021-4

3. Lien SB, Liou NH, Wu SS. Analysis of anatomic morphometry of the pedicles and the safe zone for throughpedicle procedures in the thoracic and lumbar spine. Eur Spine J. 2007;16(8):1215-1222. doi:10.1007/s00586-006-0245-2

4. Zindrick MR, Wiltse LL, Doornik A, et al. Analysis of the morphometric characteristics of the thoracic and lumbar pedicles. Spine (Phila Pa 1976). 1987;12(2):160-166. doi:10. 1097/00007632-198703000-00012

5. Olsewski JM, Simmons EH, Kallen FC, Mendel FC, Severin CM, Berens DL. Morphometry of the lumbar spine: anatomical perspectives related to transpedicular fixation. $J$ Bone Joint Surg Am. 1990;72(4);541-549. doi:10.2106/ 00004623-199072040-00011

6. Panjabi MM, Goel V, Oxland T, et al. Human lumbar vertebrae: quantitative three-dimensional anatomy. Spine (Phila Pa 1976). 1992;17(3):299-306. doi:10.1097/00007632199203000-00010

7. Jenkins TJ, Mai HT, Burgmeier RJ, Savage JW, Patel AA, Hsu WK. The triangle model of congenital cervical stenosis. Spine (Phila Pa 1976). 2016;41(5):E242-247. doi:10.1097/BRS. 0000000000001227

8. Molinari MRW, Bridwell KH, Lenke LG, Ungacta FF, Riew KD. Complications in the surgical treatment of pediatric high-grade, isthmic dysplastic spondylolisthesis: a comparison of three surgical approaches. Spine (Phila Pa 1976). 1999;15;24(16):1701-1711. doi:10.1097/00007632-19990815000012

9. Lee SH, Choi WG, Lim SR, Kang HY, Shin SW. Minimally invasive anterior lumbar interbody fusion followed by percutaneous pedicle screw fixation for isthmic spondylolisthesis. Spine J. 2004;4(6):644-649. doi:10.1016/j.spinee.2004.04. 012

10. Roy-Camille R, Saillant G, Mazel C. Internal fixation of 
the lumbar spine with pedicle screw plating. Clin Orthop Relat Res. 1986;203:7-17. doi:10.1097/00003086-198602000-00003

11. Choi HJ, Park JY, Chin DK, Kim KS, Cho YE, Kuh SU. Anatomical parameters of fifth lumbar vertebra in L5-S1 spondylolytic spondylolisthesis from a surgical point of view. Eur Spine J. 2014;23(9):1896-1902. doi:10.1007/s00586-0133111-z

12. Roussouly P, Gollogly S, Berthonnaud E, Labelle H, Weidenbaum M. Sagittal alignment of the spine and pelvis in the presence of L5-S1 isthmic lysis and low-grade spondylolisthesis. Spine (Phila Pa 1976). 2006;31(21):2484-2490. doi:10. 1097/01.brs.0000239155.37261.69

13. Been E, Li L, Hunter DJ, Kalichman L. Geometry of the vertebral bodies and the intervertebral discs in lumbar segments adjacent to spondylolysis and spondylolisthesis: pilot study. Eur Spine J. 2011;20(7):1159-1165. doi:10.1007/s00586-010-1660-y

14. Matthews PG, Phan K, Rao PJ, Ball JR. Pedicle length and degree of slip in lumbosacral isthmic spondylolisthesis. Orthop Surg. 2015;7(2):108-111. doi:10.1111/os.12173

15. Bajwa NS, Toy JO, Ahn NU. L5 pedicle length is increased in subjects with spondylolysis: an anatomic study of 1072 cadavers. Clin Orthop Rel Res. 2012;470(11):3202-3206. doi:10.1007/s11999-012-2439-8

16. Wren TAL, Ponrartana S, Aggabao PC, Poorghasamians E, Skaggs DL, Gilsanz V. Increased lumbar lordosis and smaller vertebral cross-sectional area are associated with spondylolysis. Spine (Phila Pa 1976). 2018;43(12):833-838. doi:10.1097/BRS.0000000000002480

17. Gilsanz V, Boechat MI, Gilsanz R, Loro ML, Roe TF, Goodman WG. Gender differences in vertebral sizes in adults: biomechanical implications. Radiology. 2014;190(3):678-682. doi:10.1148/radiology.190.3.8115610

Disclosures and COI: The authors received no funding for this study and report no conflicts of interest.

Corresponding Author: Dhruv K.C. Goyal, Spine Research Fellow, Rothman Institute, 925 Chestnut St, 5th Floor, Philadelphia, PA 19107. Phone: (937) 830-7110; Email: dhruvkcgoyal@ gmail.com.

Published 16 April 2021

This manuscript is generously published free of charge by ISASS, the International Society for the Advancement of Spine Surgery. Copyright (C) 2021 ISASS. To see more or order reprints or permissions, see http://ijssurgery.com. 